\title{
An Anatomical Study of the Muscles Innervated by the Masseteric Nerve
}

\author{
By

\begin{abstract}
Takashi SHIMOKAWA ${ }^{1,2}$, Keiichi AKITA ${ }^{2}$, Kunimichi SOMA ${ }^{1}$ and Tatsuo SATO ${ }^{2}$
\end{abstract} \\ ${ }^{1}$ First Department of Orthodontics, Faculty of Dentistry, Tokyo Medical and Dental University, Tokyo 113-8549, Japan \\ ${ }^{2}$ Second Department of Anatomy, School of Medicine, Tokyo Medical and Dental University, Tokyo 113-8519, Japan \\ - Received for Publication, October 13, 1998 -
}

Key Words: Masseter, Zygomaticomandibularis, Masseteric nerve, Nerve innervation, Human gross anatomy

\begin{abstract}
Summary: For an accurate assessment of jaw movement, it is critical to understand the comprehensive formation of the masseter. Detailed dissection was performed on fifteen head halves of eight Japanese cadavers in order to obtain precise anatomical information of the course and distribution of the masseteric nerve in the masseter, especially in the $\mathrm{zy}$ gomaticomandibularis (ZM). Based on detailed innervation investigation, the main trunk of the masseteric nerve ran between $\mathrm{ZM}$ and the masseter, and the anterior region of $\mathrm{ZM}$ was closely related to the lateral layer of the masseter rather than the medial layer. Considering the positional relationships between the muscles and the innervating branches, it might be proposed that the muscle masses of $\mathrm{ZM}$ and the masseter migrate from the posterior side of the temporalis anterolateralward during development. This model is in agreement with the findings in that no nerve branch was observed between the temporalis and $\mathrm{ZM}$.
\end{abstract}

The architecture of the masticatory muscles is highly complex. The muscles, especially the temporalis and the masseter, are considered to be architecturally and functionally compartmentalized muscles (Herring, 1980; Wineski and Gans, 1984; English, 1985; Herring and Wineski, 1986; Herring et al., 1989). Compartmentalization can function to separate groups of muscle fibers with varying lines of action, allowing the muscles to change their direction of contractions by recruiting the fibers differentially.

The architecture of the muscle bundles of the masseter has been examined in many studies, and the masseter is generally classified into two layers (e.g. Sicher and DuBrul, 1970; Leonhardt et al., 1987) or three layers (e.g. Clemente, 1985; Williams et al., 1995) based on the direction of the muscle bundles. Yoshikawa and Suzuki (1962) classified the masseter into five layers based on the relationships between tendinous and muscular substances. Lam et al. (1991) reported the tendon structure of the human masseter by three-dimensional reconstructed images from magnetic resonance imaging (MRI), and identified four tendon planes in each masseter muscle. The stratified structure of the masseter is still unclear, and the number of layers may change depending on the criteria for the identification of the layers.

The muscle bundles between the temporalis and the masseter are frequently described, and termed in various ways: the zygomaticomandibularis (Toldt, 1904; Sicher and DuBrul, 1970; Tomo, 1990), the maxillomandibularis (Yoshikawa and Suzuki, 1962), the accessory head of the temporalis (Leonhardt et al., 1987) and the deep part of the masseter (Eisler, 1912). The bundles are frequently innervated by both the masseteric nerve and the posterior deep temporal nerve which mainly innervates the posterior third of the temporalis. Tomo (1990) described that the bundles are considered as a transitional muscle. It is suggested that the bundles occupy a critical position between the masseter and the temporalis. Here, the bundles are termed zygomaticomandibularis as adapted by Sicher and Dubrul (1970) in order to distinguish them from the masseter and the temporalis for the convenience of the explanation.

In electrophysiological studies, the compartmentalization of the motor unit territory of the human masseter muscle has been noted especially in rela- 
tion to the internal anatomy of the muscle (Stålberg and Eriksson, 1987; McMillan and Hannam, 1991; Blanksma et al., 1992; Tonndorf and Hannam, 1994; Tonndorf et al., 1994). However, there has been little information on the spatial arrangement of the nerve branches to the masseter which connect the motor units. Herring et al. (1989) and Tomo (1990) showed that branches which innervate the anterior part of the masseter penetrate and innervate the zygomaticomandibularis before entering the masseter. It has been suggested that there is a close relationship between the zygomaticomandibularis and the anterior part of the masseter.

In the present study, the masseter, the zygomaticomandibularis and the temporalis were removed en bloc from the bony elements, and the detailed innervation patterns were examined. We report the positional relationships among the muscles and their innervating nerves, and discuss the relationships among the muscles.

\section{Materials and Methods}

Fifteen halves of eight Japanese cadavers (four males and four females) fixed in $10 \%$ formalin and preserved in $30 \%$ alcohol were examined. In order to examine the masseter, zygomaticomandibularis and temporalis in detail, the zygomatic arch was removed from the outside, and the bony elements of the cranium were removed from the inside. Before removal of the bony elements, care was taken so as not to divide the muscles in order to preserve small twigs to the muscles. After investigation of the nerve branches which entered the masseter and zygomaticomandibularis, the masticatory muscles were removed en bloc with the mandibular nerve and its branches. The specimens were immersed in water for further dissection, and the intramuscular nerve distributions of the muscles were examined in detail under a binocular microscope, and recorded.

\section{Results}

\section{The masseter and the zygomaticomandibularis}

Based on the directions of the muscle bundles of the masseter, the muscle seemed to be composed of several layers, and definite borders between layers were observed from the lateral aspect (Fig. 1A). No clear border was identified in the muscular parts in three specimens $(20.0 \%)$, however the direction of the tendinous parts clearly delineated the borders to underlying muscular parts (Fig. 1B). The number of layers observed from the lateral aspect of the masseter was two $(20.0 \%)$, three $(66.6 \%)$ or four $(13.3 \%)$.

Figure 1A shows a typical case of the presumptive layer structure. In this specimen, the muscle seemed to be composed of three layers: lateral, middle and medial layers. The lateral layer originated from the anterior third of the lateral surface of the zygomatic arch, ran infero-posteriorly, and inserted into the angle of the mandible. The middle layer originated from the middle third of the inferior border of the zygomatic arch, and inserted into the middle region of the lateral surface of the ramus of the mandible. The medial layer originated from the posterior third of the inner surface of the arch, ran inferiorly and inserted into the lateral surface of the coronoid process. Therefore, the more lateral part of the masseter originated from the more anterolateral region of the zygomatic arch, ran more posteriorly, and inserted into the lower region of the lateral surface of the ramus of the mandible. In addition, the more lateral part occupied the more anterolateral region of the masseter.

After removal of the zygomatic arch and the deep fascia of the temporalis, the zygomaticomandibularis was observed medial to the main trunk of the masseteric nerve (Fig. 1C). The muscle was situated between the masseter and the temporalis. The anterior border of the zygomaticomandibularis adjoined the medial surface of the anterior region (lateral layer) of the masseter, and the posterior border adjoined the posterolateral surface of the posterior region of the temporalis (Fig. 1D). Interestingly, no nerve branch was found between the zygomaticomandibularis and the masseter. The zygomaticomandibularis originated from the posteriormost region of the zygomatic arch and the medial surface of the aponeurosis of the temporalis, and inserted into the lateral surface of the coronoid process and the aponeurosis of the temporalis. The muscle was generally identified as two to five thin layers based on the muscle bundle direction; the borders between these layers could be observed from the posterolateral aspect of the muscle (Fig. $2 \mathrm{~A})$. Number of the layers was two $(6.7 \%)$, three $(26.7 \%)$, four $(40.0 \%)$ or five $(26.7 \%)$.

\section{Distribution of the masseteric nerve}

The masseteric nerve originated as a common trunk with the posterior deep temporal nerve from the mandibular nerve. The main trunk of the masseteric nerve wound around the posterior margin of the temporalis, and passed through the mandibular notch to reach the masseter. The main trunk ran anteroinferiorward between the masseter and the zygomaticomandibularis, and gave off muscular 
twigs. The twigs from the main trunk to the masseter entered its medial surface (Fig. 2A), and the twig that arose from the more distal part of the main trunk entered the more anteroinferior region of the masseter (Figs. 3-5). The twigs which arose from the proximal part of the main trunk distributed to the medial layer of the masseter. The twigs which arose from the middle part of the main trunk distributed to the middle layer of the masseter, and ran posteroinferiorward in the layer. The twigs that arose from the distal part distributed to the lateral layer, and also ran posteroinferiorward in the layer. The twigs that innervated the medial or middle layer frequently ran lateralward, and also innervated the adjacent layer (Fig. 2B). In addition, the small twigs that penetrated the zygomaticomandibularis entered the anterosuperior part of the masseter.

The twigs to the zygomaticomandibularis arose medially from the main trunk, ran between these layers (Fig. 2A), and innervated them from both medial and lateral surfaces of the presumptive layers (Figs. 3-5). In general, the twigs arose from the more distal part of the main trunk of the masseteric nerve and innervated the more lateral layer of the zygomaticomandibularis. However, the twigs arose from the proximal part of the main trunk, innervated the anterior regions of the layers of the muscle, penetrated the muscle, and then innervated the anterosuperior part of the masseter (Figs. 3-5). The twigs to the medial layer of the zygomaticomandibularis frequently arose from the posterior deep temporal nerve (Figs. 3-4).

\section{Discussion}

Numerous studies have shown the stratified structure of the temporalis and the masseter, and the layers of these muscles are classified into various ways. These differences in classifications lie in the definition of the muscle layer of the border region between the two muscles: 1) as independent muscle (Toldt, 1904; Yoshikawa and Suzuki, 1962; Sicher and DuBrul, 1970; Tomo, 1990), 2) a part of the masseter (Sappey, 1876; Clemente, 1985; Williams et al., 1995) or 3) a part of the temporalis (Leonhardt et al., 1987). Most of these studies are based on the muscle bundle direction, merely the external appearance. In the present study, we considered the border muscular region as an independent muscle, according to the relationship to the main trunk of the masseteric nerve and the innervation pattern. Here, we call the region the zygomaticomandibularis as termed by Sicher and DuBrul (1970).
Recently, from the clinical viewpoint, the assessment of the function and movement of the jaw muscles by electrophysiological techniques has been of great importance (Tonndorf and Hannam, 1994; Tonndorf et al., 1994). Accordingly, the functional units of the muscles have been examined in relation to the internal anatomy. However, the detailed relationships between the layer structure and the innervation are still unclear. In the present study, the innervating branches of the masseter, the zygomaticomandibularis and the temporalis were examined after removal from the bony elements en bloc. The main trunk of the masseteric nerve ran between the zygomaticomandibularis and the masseter. The twigs to the zygomaticomandibularis frequently penetrated the muscle, and innervated the anterosuperior part of the masseter. The twigs arose from the more distal part of the main trunk of the masseteric nerve, entered the more anteroinferior part of the masseter, ran lateroposteriorward, and innervated the more lateral layer of the muscle. In addition, the twigs frequently penetrated the tendons in the masseter, and hence small twigs were found to pierce the layers. Therefore, interestingly the zygomaticomandibularis has a close relationship to the lateral layer of the masseter rather than to the middle or medial layers, and the distribution of the innervating branches is not limited to the layers divided by the tendons.

Figure 6 schematically represents the relationships among the masseter, the zygomaticomandibularis, the temporalis, and the masseteric nerve. Interestingly, the innervating branches are generally distributed antero-infero-lateralward, and the layers of the masseter have a U-shaped form. These findings are in agreement with Toldt (1904) and Tomo (1990). Edgeworth (1914) proposed that the anlage of the masseter and the zygomaticomandibularis arises from the posterior part of the common anlage of the masticatory muscles, and migrates anterolateralward. Figure 7 schematically represents a possible model of the development of the masseter, based on the findings of the nervemuscle relationships of the present study and the findings of Edgeworth (1914). The muscle mass of the masseter moves from the posterior side of the temporalis anteriorward. During the migration it is suggested that the muscle bundles medial to the main trunk of the masseteric nerve might form the posteromedial muscle bundles and the muscle bundle lateral to the main trunk might form the masseter. This model is in agreement with the findings that no nerve branch was observed between the temporalis and the zygomaticomandibularis. With functional adaptation, both the masseter and the zygomaticomandibularis might take a variety of 


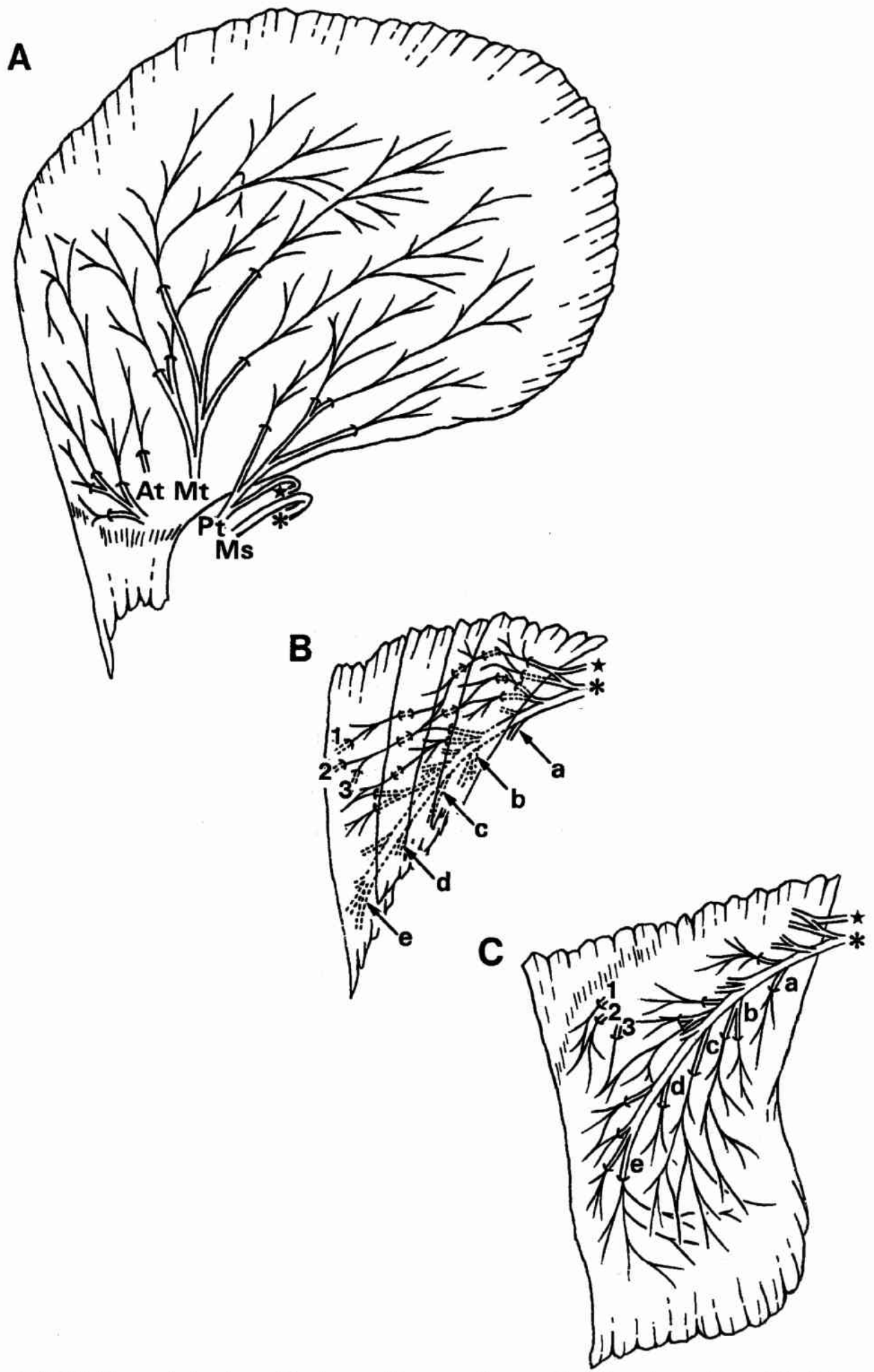

Fig. 3. Specimen 1 (right). The medial surface of the temporalis, zygomaticomandibularis and masseter, and the intramuscular nerve distribution are shown. Asterisks and stars indicate continuation of the nerves, and the numbers and alphabets of the twigs are common in Figs. B and C. [This holds also for Specimen 2 and 3.] A) The medial surface of the temporalis. The muscle was innervated by the three main nerves: the anterior, middle and posterior deep temporal nerves. One twig (star) of the posterior deep temporal nerve wound around the posterior margin of the muscle with the masseteric nerve. B) The medial surface of the zygomaticomandibularis. The muscle seemed to be composed of four presumptive layers. The more distal twig innervated the more anterolateral layer of the bundle. The most medial layer was innervated by the united branch of the posterior deep temporal and masseteric nerves. The twigs which innervated the most lateral layer penetrated the layer to enter the anterosuperior part of the masseter. C) The medial surface of the masseter. The more distal branches were distributed in the more antero-infero-lateral part of the muscle. The anterosuperior part of the masseter was innervated by the twigs which penetrated the most lateral layer of the zygomaticomandibularis from the medial surface. 


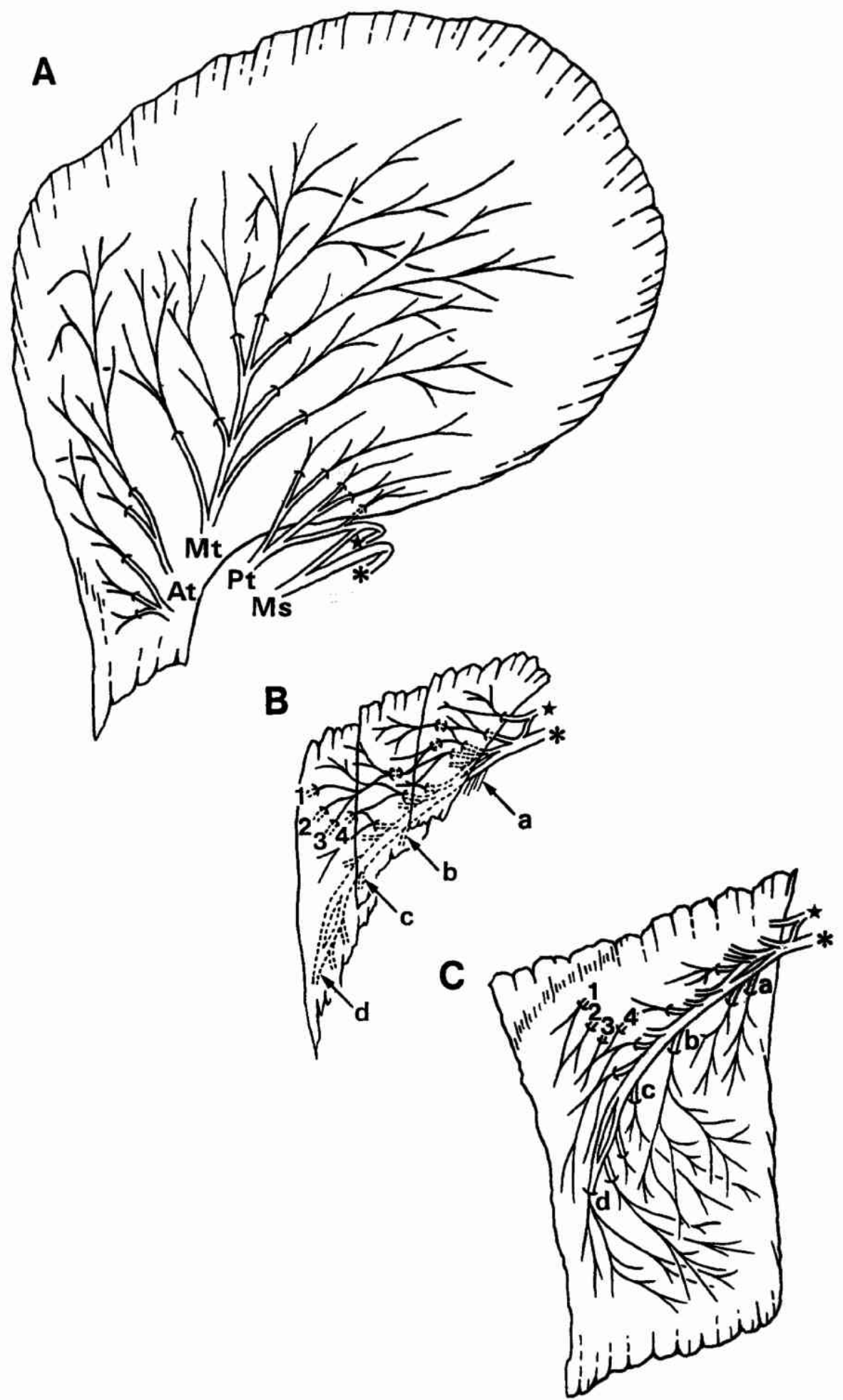

Fig. 4. Specimen 2 (right). A) The temporalis. The most posterior branch of the posterior deep temporal nerve innervated the muscle from the posterolateral surface. B) The zygomaticomandibularis. In this specimen, the muscle was composed of three presumptive layers. The most medial layer was innervated by the united branch of the masseteric and posterior deep temporal nerves from the medial surface of the layer. C) The masseter. 




Fig. 5. Specimen 3 (right). A) The temporalis. The twigs of the posterior deep temporal and masseteric nerves united to innervate the posterior part of the temporalis. B) The zygomaticomandibularis. In this specimen, four presumptive layers were observed. C) The masseter. 


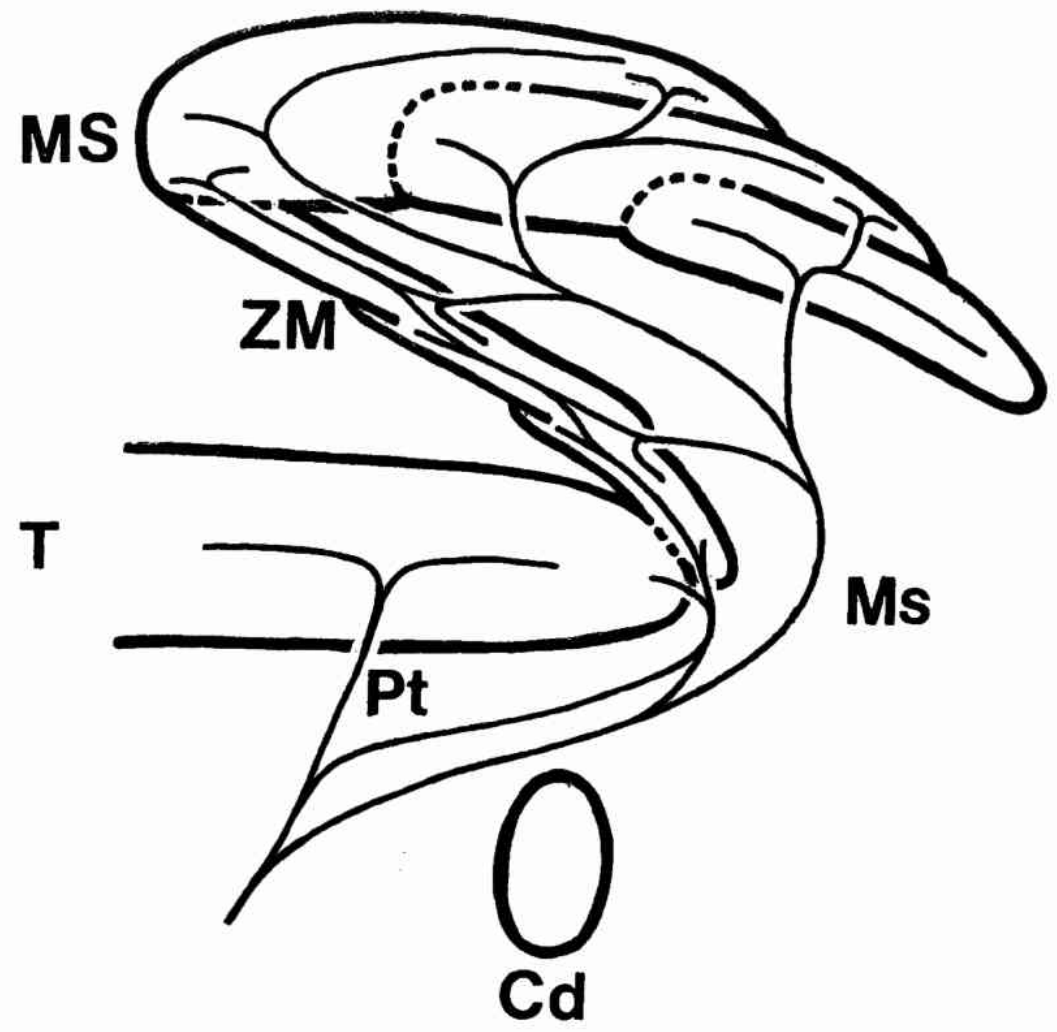

Fig. 6. Schematic transverse section showing the pattern of innervation of the masseter and the zygomaticomandibularis. In this section, the muscle is classified into three presumptive muscle layers.

A



B 
directions. Since the stratified structure of the muscles does not correspond to the pattern of the intramuscular nerve distribution, it might not be essential for the muscle structure.

\section{References}

1) Blanksma NG, Van Eijden TM and Weijs WA. Electromyographic heterogeneity in the human masseter muscle. J Dent Res 1992; 71:47-52.

2) Clemente CD. Gray's Anatomy. 30th ed. pp 447-452, Lea \& Febiger, Philadelphia, 1985.

3) Edgeworth FH. On the development and morphology of the mandibular and hyoid muscles of mammals. Quart $\mathrm{J}$ Microsc Sci 1914; 59:573-645.

4) Eisler P. Die muskeln des Stammes. Bardeleben K. v., Handbuch der Anatomie des Menschen. Bd. 2/2/1. pp 197220, Gustav Fischer, Jena, 1912.

5) English AW. Limbs vs. jaws: Can they be compared? Am Zool 1985; 25:351-363.

6) Herring SW. Functional design of cranial muscles: Comparative and physiological studies in pigs. Am Zool 1980; 20:283-293.

7) Herring SW and Wineski LE. Development of the masseter muscle and oral behavior in the pig. J Exp Zool 1986; 237:191-207.

8) Herring SW, Wineski LE and Anapol FC. Neural organization of the masseter muscle in the pig. J Comp Neurol 1989; 280:563-576.

9) Lam EW, Hannam AG and Christianson EL. Estimation of tendon-plane orientation within human masseter muscle from reconstructed magnetic resonance images. Arch Oral Biol 1991; 36:845-853.

10) Leonhardt $H$, Tillman B, Tondury $G$ and Zilles K. Rauber/ Kopsch, Anatomie des Menschen. Vol. 1. pp 738-744, Thieme, Stuttgart, 1987.

11) McMillan AS and Hannam AG. Motor-unit territory in the human masseter muscle. Arch Oral Biol 1991; 36:435-41.

12) Sappey PC. Traité d'anatomie descriptive. 3rd ed., Vol. 2. pp 135-142, Adrien Delahaye, Paris, 1876.

13) Sicher H and DuBrul EL. Oral Anatomy. 5th ed. pp 120 126, Mosby, St. Louis, 1970.
14) Stålberg E and Eriksson PO. A scanning electromyographic study of the topography of human masseter single motor units. Arch Oral Biol 1987; 32:793-797.

15) Toldt C. Der Winkelfortsatz des Unterkiefers beim Menschen und bei den Säugetieren und Beziehungen der Kaumuskeln zu demselben. Teil 1. Sitz Berichte d Mathem Naturw Klasse, pp 43-108, 1904.

16) Tomo $\mathrm{S}$. Morphological classification of the mastication muscles based on their innervation. Ochanomizu Med J Tokyo 1990; 38:57-71. (in Japanese)

17) Tonndorf ML and Hannam AG. Motor unit territory in relation to tendons in the human. 1994; 17:463-443.

18) Tonndorf ML, Connell DG and Hannam AG. Stereotactic location of EMG needle electrode scans relative to tendons in the human masseter muscle. J Neurosci Meth 1994; 51:77-82.

19) Williams PL, Bannister LH, Berry MM, Collins P, Dyson M, Dussek JE and Ferguson MW. Gray's Anatomy. 38th ed. pp 799-802, Churchill Livingstone, Edinburgh, 1995.

20) Wineski LE and Gans C. Morphological basis of the feeding mechanics in the shingle-back lizard Trachydosaurus rugosus (Scincidae, Reptilia). J Morphol 1984; 181:271295.

21) Yoshikawa $T$ and Suzuki $T$. The lamination of the human masseter - The new identification of $\mathrm{M}$. temporalis superficialis, M. maxillomandibularis and M. zygomaticomandibularis in the human anatomy. Acta Anat Nippon 1962; 37:260-267. (in Japanese with English abstract)
Abbreviations for figures
At anterior deep temporal nerve
Cd condyle
MS masseter
Ms masseteric nerve
Mt middle deep temporal nerve
$\mathrm{Pt}$ posterior deep temporal nerve
$\mathrm{Ra}$ ramus of mandible
$\mathrm{T}$ temporalis
$\mathrm{Za}$ zygomatic arch
ZM zygomaticomandibularis

\section{Explanation of Figures}

\section{Plate I}

Fig. 1. Photographs of the lateral surface of the masseter. A) Specimen 1 (right). In this specimen the muscle bundles were classified into three layers based on the muscle bundle directions. The arrows (1 to 3 ) indicate the main muscle bundle directions. B) Specimen 9 (right). In this specimen, it was difficult to classify the muscle bundles into layers, however the directions of the tendinous parts could be identified because of the clear borders delineating the underlying muscular parts. The arrows (1 to 3$)$ indicate the main tendinous parts and the muscle bundle directions. C) Specimen 5 (right). After removal of the masseter, the zygomaticomandibularis was observed lateral to the temporalis and medial to the main trunk of the masseteric nerve. D) Specimen 9 (left). Anterior aspect of the temporalis, the zygomaticomandibularis and the masseter. The anterior border of the zygomaticomandibularis adjoined the medial surface of the masseter. 


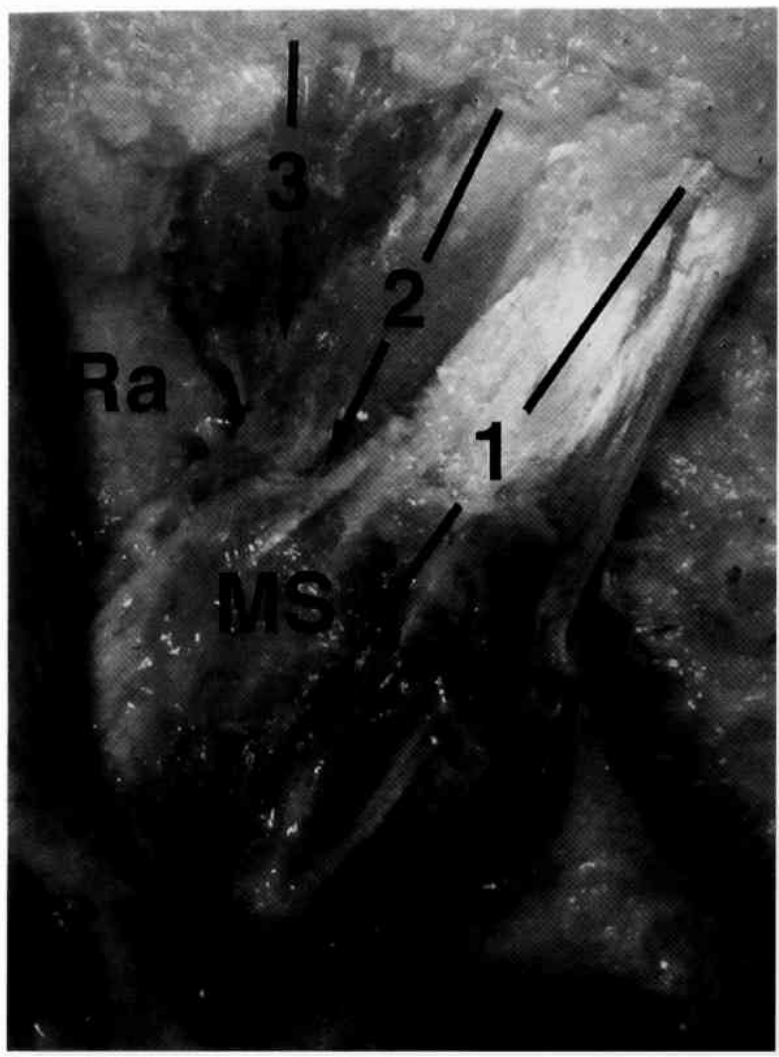

A

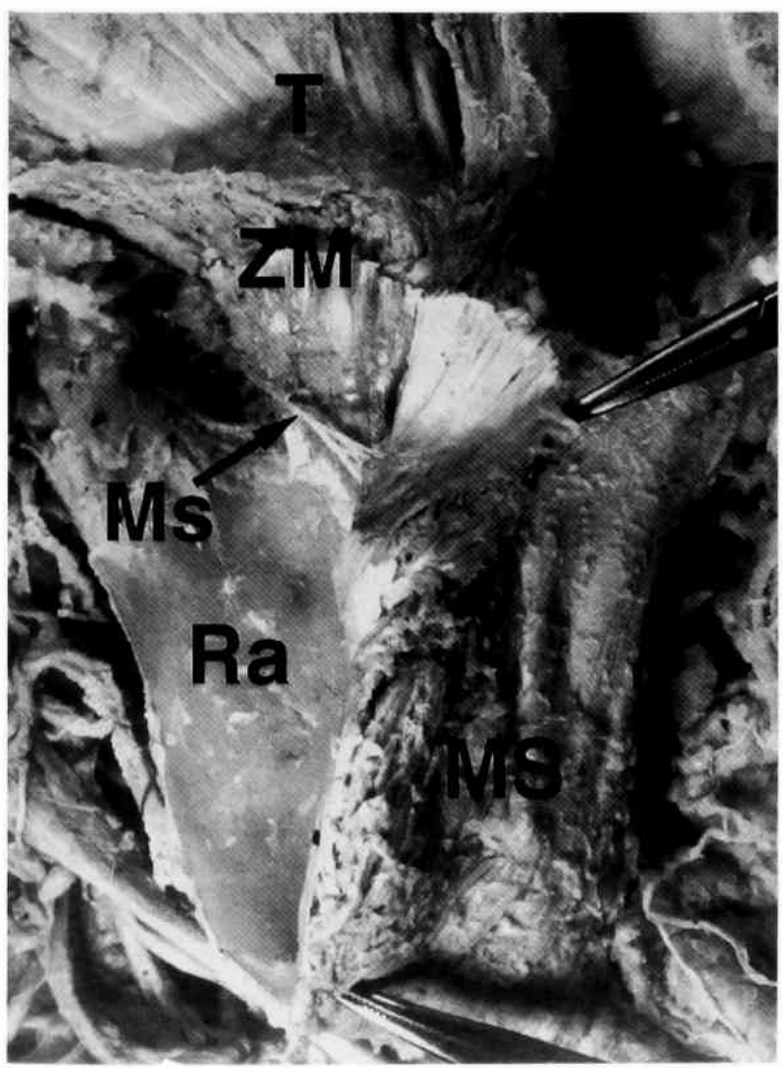

C

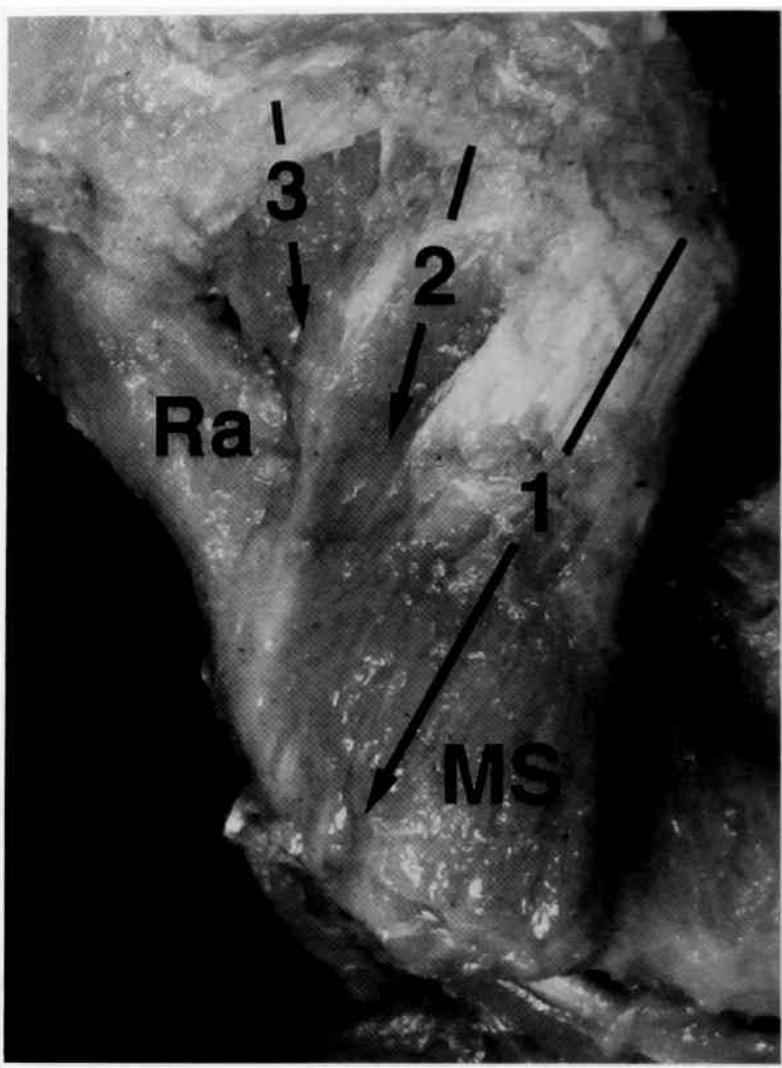

$\mathrm{B}$

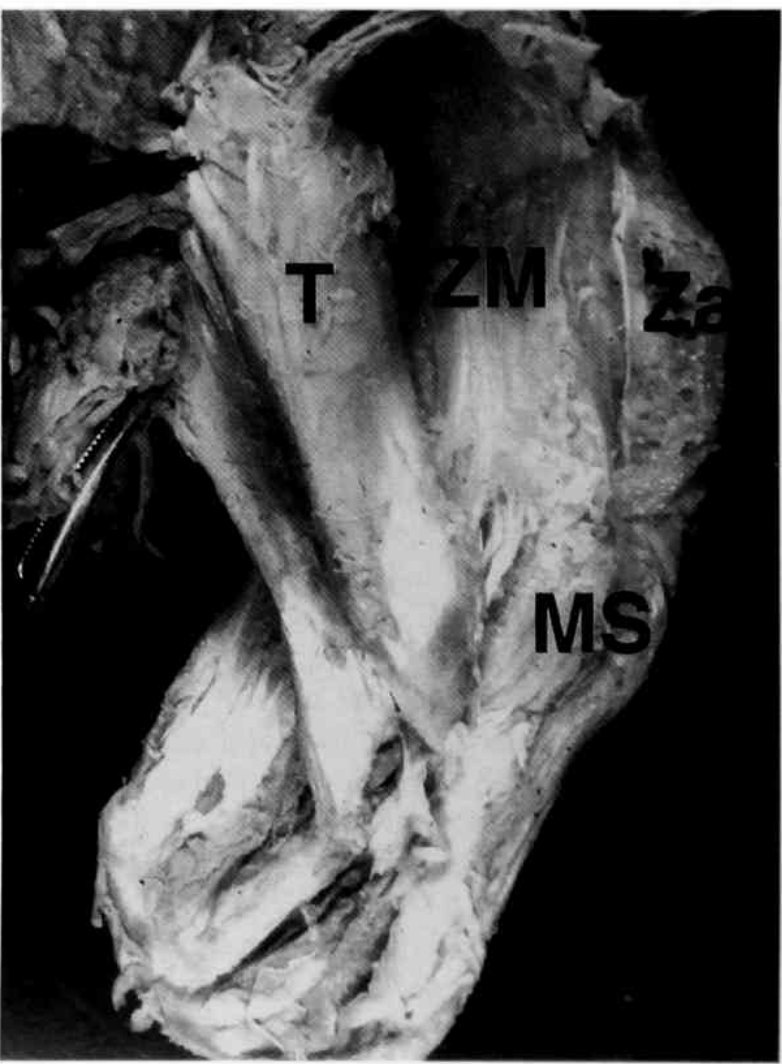

$\mathrm{D}$ 
Plate II

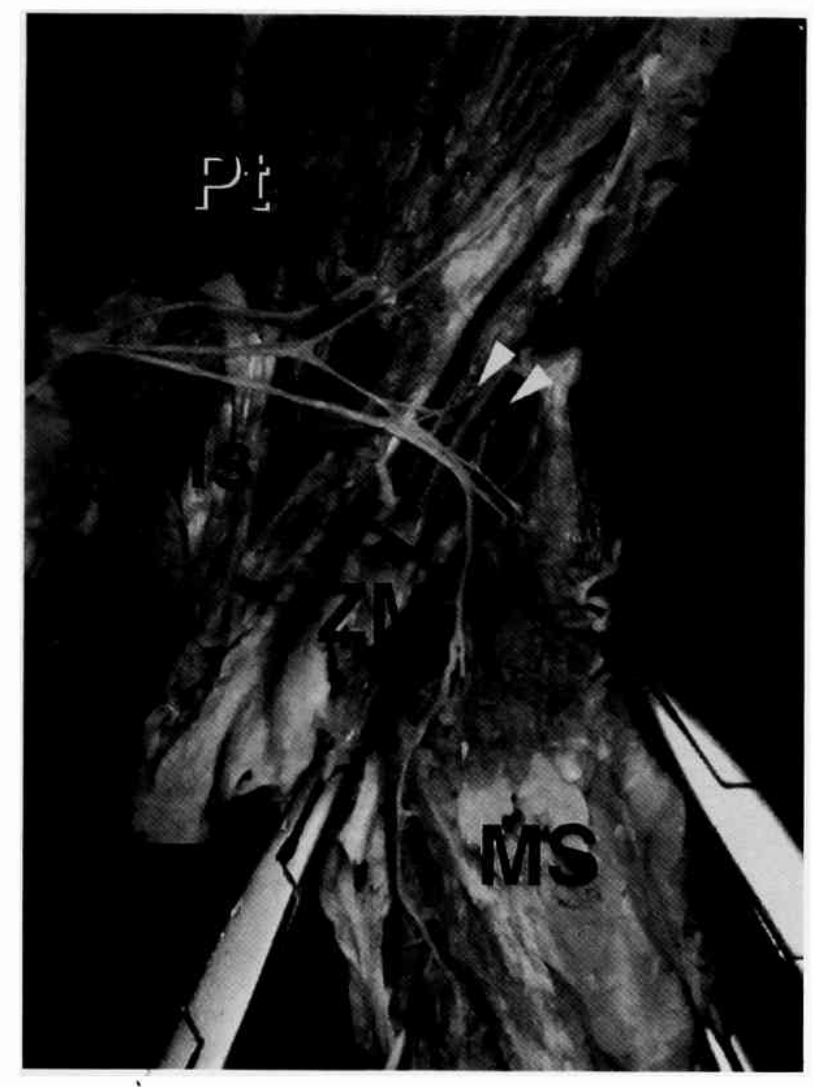

A

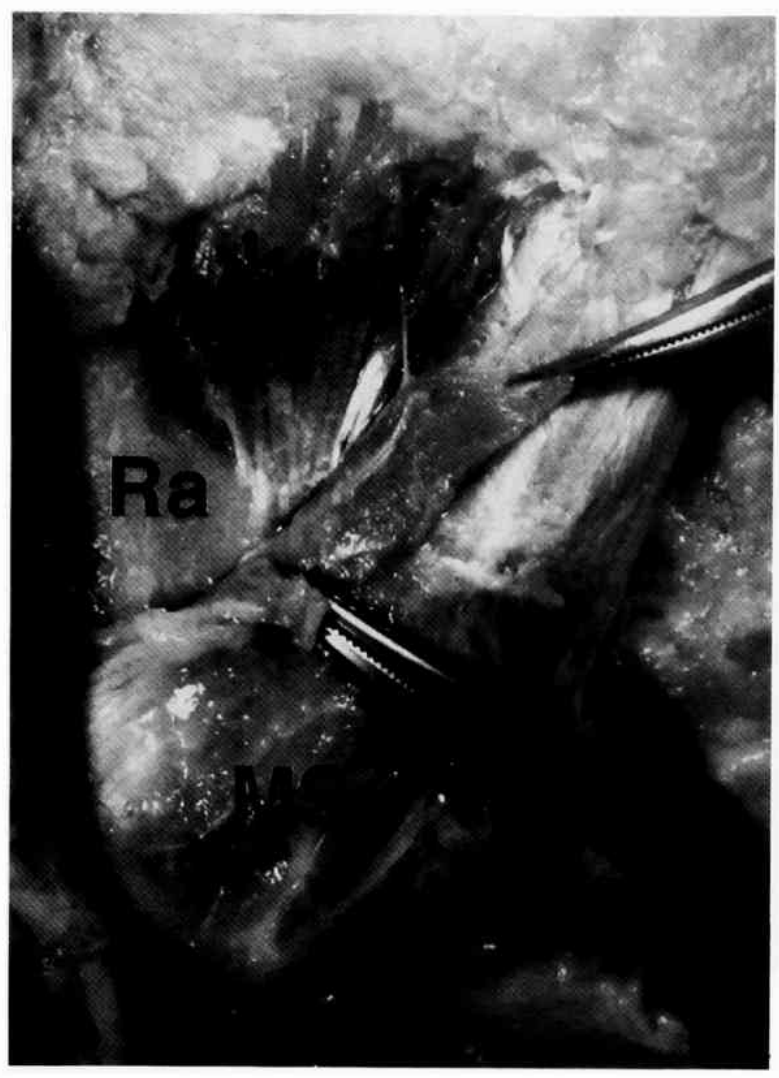

$\mathrm{B}$

\section{Plate II}

Fig. 2. A) Specimen 1 (right). Photographs of the zygomaticomandibularis. The posterior region of the muscle and the medial surface of the masseter are shown. The zygomaticomandibularis was innervated by the branches from the masseteric nerve (indicated by white arrowheads), and the nerve ran between the muscle and the masseter. B) Photograph of the masseter seen from lateral in specimen 1. A twig (asterisk) which pierced the medial layer entered the medial surface of the middle layer to innervate it. 